\title{
Bringing Theory to Life: Strategies that Make Culturally Responsive Pedagogy a Reality in Diverse Secondary Classrooms
}

\author{
Socorro G. Herrera \\ Melissa A. Holmes \\ Shabina K. Kavimandan \\ Kansas State University \\ U. S. A.
}

Preparing U.S. teachers for effectiveness with culturally and linguistically diverse (CLD) secondary students remains a challenge, given the relative homogeneity of educators and their enculturation to an educational system based on European American norms and values. Although culturally responsive pedagogy has emerged as a promising avenue for promoting student achievement, instructional tools are needed to support application of theory in multicultural classrooms. In this paper, we provide a framework for linguistic and academic development, contextualized within a larger model of biography-driven instruction. Instructional strategies implemented throughout the lesson are described, and their usefulness for improving teacher performance is explored.

\author{
Forging a Path \\ Biography-Driven Practices \\ A Framework for Linguistic and Academic Development \\ Biography-Driven Instruction Strategies \\ Current Research on Biography-Driven Instruction Strategies \\ Conclusion \\ Notes \\ References
}

For over 50 years the field of education has sought to prepare both preservice and inservice educators for the diversity represented in classrooms across the United States. Although the number of culturally and linguistically diverse (CLD) students continues to increase, teacher demographics and the dynamics of classroom instruction have seen little change. For example, $84 \%$ of public school teachers in the nation are White (Feistritzer, 2011). By contrast, over $46 \%$ of public preK-12 students are Black, Hispanic, Asian, Pacific Islander, American Indian/Alaska Native, or two or more races (Aud et al., 2011). Teachers entering the profession through traditional and alternative preparation programs also continue to remain relatively homogenous, that is to say primarily White and female (Feistritzer, 2011). 
In addition to racial and ethnic diversity, students bring many types of language backgrounds. More than 150 languages are spoken by English language learning (ELL) students across the country, with Spanish being the predominant language (spoken by over $77 \%$ of ELLs), followed by Vietnamese and Chinese. In seven states (Alaska, Hawaii, Maine, Montana, North Dakota, South Dakota, Vermont), Bosnian, Somali, or an indigenous language is the top language spoken (Batalova \& McHugh, 2010).

The current state of mismatch between teacher and student demographics as well as persistent gaps in student achievement, especially those related to ELL students and their non-ELL peers (Aud et al., 2011), has turned the spotlight on multicultural education and its outcomes for learners today. Questions abound concerning teachers' readiness for multicultural and multilingual education and advocacy in 21st-century classrooms. As a field we must ask: In what ways do today's educators demonstrate the knowledge, skills, and dispositions essential to efficacy in such environments? The authors of this paper present the results of recent research on an instructional framework that seeks to bridge past and current theoretical frameworks of multicultural education and provide tools for increasing teacher effectiveness with CLD students.

\section{Forging a Path: \\ Contextualizing Multicultural Education in Classroom Practice}

Banks $(1989,1998)$ led the field with his groundbreaking work that helped educators see how their instruction with CLD students and their efforts to diversify the school curriculum might be conceptualized along a continuum of approaches (contributions, ethnic additive, transformation, and decision-making and social action). Banks supported teachers in developing knowledge about the characteristics of curricula that would be more likely to promote learning for all learners. Ideally, curricula are designed to support the exploration and identification of beliefs, assumptions, and frames of reference that underlie and influence perceptions of knowledge within a discipline. Moreover, Banks urged teachers to make instructional accommodations to advance the learning and achievement of all students, especially those who bring an element of diversity to the classroom.

Additional authors such as Nieto (2002) focused educators' attention on the intersections of language and culture in students' linguistic and academic development. She emphasized the relationships between teachers and students and recognized the necessity of considering sociopolitical dynamics that influence all learning endeavors. Like Banks, she understood the need for educators to actively promote antiracist behaviors and attitudes among students in order to build a community of learners dedicated to making positive changes in the world. Always at the forefront was the call for teachers to value students' identities and utilize their assets and resources in the classroom. 
Researchers such as Gay (2002) continued to build upon the theoretical foundations of multicultural education but also recognized teachers' philosophical beliefs and knowledge about multicultural and multilingual learners needed to translate to changes in pedagogical skills and practices. To support such transfer of knowledge to the classroom, Gay promoted implementation of culturally responsive (sometimes referred to as culturally relevant) pedagogy. At the most basic level, culturally responsive teaching can be defined as "using the cultural characteristics, experiences, and perspectives of ethnically diverse students as conduits for teaching them more effectively" (Gay, 2002, p. 106). More recently, the National Center on Response to Intervention (2010) has gone beyond typical discussions of culturally responsive pedagogy to include the often-overlooked aspect of students' language (Santamaria, 2009), stating that culturally and linguistically responsive educational practices involve:

...purposeful consideration of the cultural, linguistic, and socioeconomic factors that may have an impact on students' success or failure in the classroom. Attention to these factors, along with the inclusion of cultural elements in the delivery of instruction, will help make the strongest possible connection between the culture and expectations of the school and the culture(s) that students bring to the school. Instruction should be differentiated according to how students learn, build on existing student knowledge and experience, and be language appropriate. (p. 9)

Many authors and researchers describe at length the benefits of these teaching practices for CLD students (e.g., Ladson-Billings,1995; Nieto, 2000). A culturally responsive perspective allows teachers to move beyond lists of culture-specific do's and don'ts that ignore within-group diversity. It also stands in stark contrast to highly popularized deficit perspectives of students and families in poverty (e.g., the critical analysis of Ruby Payne's professional development by Bomer, Dworin, May, \& Semingson, 2008).

Yet, to fully understand what such theory means for daily instruction, teachers need to actually experience this type of instruction. One of the difficulties with such modeling is the limited number of published examples of implementation that teacher educators have to draw upon. Morrison, Robbins, and Rose (2008) examined 45 studies that explored culturally responsive/relevant pedagogy. They noted that many of these studies, however, took place in contexts with relatively homogenous groups of students (e.g., mostly African American or Latina/o students). The cultural and linguistic diversity of student populations in US schools today requires that teacher preparation programs model practices that can be implemented with students across cultural and linguistic backgrounds. In the subsequent sections, we discuss a tangible way to implement culturally responsive pedagogy in truly multicultural classrooms. 


\section{Biography-Driven Practices: Bringing CLD Students to the Center of Instruction}

Biography-driven instruction (Herrera, 2010; Herrera, Kavimandan, \& Holmes, 2011) is a model of culturally-responsive pedagogy that draws on the work of many others who have devoted their careers to advancing our understanding of the conditions that promote learning and second language acquisition and, most importantly, allow students to flourish. Examples include:

- Gay's (2000) insights into culturally-responsive teaching

- Krashen's (1984/2002) input hypothesis

- Marzano, Gaddy, and Dean's (2000) work with learning strategies

- Moll, Amanti, Neff, and Gonzalez' (1992) funds of knowledge

- Thomas and Collier's (1997) understanding of student realities that influence second language acquisition processes

- Sousa's (2006) understanding of how the brain learns

- Tomlinson's (2001) vision for differentiated instruction

- Vygotsky's (1978) zone of proximal development

At the core, biography-driven instruction (BDI) involves getting to know students holistically in order to be truly responsive to their cultural and linguistic assets and needs. Teachers explore the sociocultural, linguistic, cognitive, and academic dimensions of the CLD student biography (Herrera \& Murry, 2011) to answer the following types of questions:

- Sociocultural: What brings students life, laughter, and love?

- Linguistic: In what ways do students use their first language (L1) and second language (L2) for comprehension, communication, and expression?

- Cognitive: How do students know, think, and apply?

- Academic: To what degree do students have access, engagement, and hope?

With answers to questions such as these, teachers envision how their instruction might respond more proactively to the diversity of student biographies present in the learning community.

When implementing BDI, teachers create a low-risk learning environment in which students feel safe to engage in the lesson and share what they know with the teacher and their peers, trusting that their culture-bound ways of knowing, learning, and applying will be respected and capitalized on in the learning process. Teachers foster a supportive classroom ecology by making their teaching transparent for students; they share the goals and tasks of the 
lesson, creating a road map for learners that tells them the destination and what will happen along the way. They design classroom contexts that (a) make optimal use of the physical setting and grouping configurations; (b) are guided by standards, curricula, and objectives that reflect high expectations; and (c) communicate caring through planned instructional accommodations for students' biographies. Ultimately, instruction that systematically attends to learners and leverages their diverse sociocultural, linguistic, cognitive, and academic assets in culturally responsive ways can be considered biography-driven.

\section{A Framework for Linguistic and Academic Development}

To support secondary teachers as they work to promote linguistic and academic development among CLD learners, we propose use of a framework that applies the principles of BDI through three interrelated lesson phases: Activation (before), Connection (during), and Affirmation (after) (Herrera, Kavimandan, \& Holmes, 2011). In each of these phases, the teacher assumes different roles that work together to support student learning. The subsequent sections provide a brief overview of the Activation, Connection, and Affirmation phases of the lesson.

\section{Activation Phase}

In the Activation phase, the teacher uses activities and prompts that have been purposefully designed to access the knowledge and experiences that students bring to the topic and/or key vocabulary of the lesson. The importance of activating and preassessing this existing knowledge is well documented (Bauer \& Manyak, 2008; Herrera, Murry, \& Cabral, 2007; Marzano et al., 2000; Tomlinson \& McTighe, 2006; Smith, diSessa, \& Roschelle, 1993/1994; Waxman \& Tellez, 2002). Although the term background knowledge is sometimes used to refer to this accumulation of knowledge, ambiguity in the field surrounding the term often translates to only minimal types of information being accessedgenerally those types of knowledge that have been valued historically in schools and classrooms. What often go untapped are the cultural and linguistic knowledge bases that enable teachers to make their instruction more relevant to individual learners, especially those learners who bring socialization experiences that differ from those of dominant culture and language groups. When implementing BDI, teachers explicitly encourage students to document their funds of knowledge (home) (Moll et al., 1992), prior knowledge (community), and academic knowledge (school). These three knowledge systems together comprise a student's background knowledge (Herrera, 2010).

During the Activation phase, the teacher primarily performs the role of an observer. Students record their background knowledge using their native 
language (L1), English (L2), or non-linguistic representations. In this way, all students are held accountable for their engagement in the learning process. Students also have opportunities to discuss their knowledge with peers in pairs or small groups. While students are performing these tasks, the teacher listens and documents insights into students' biographies and background knowledge. The teacher is then in the position to maximize this knowledge in building a bridge between what is known and what is unknown about the new concepts, vocabulary, and processes to be taught.

\section{Connection Phase}

In the Connection phase, the teacher serves as a facilitator for student learning. He or she promotes the engagement of students, builds classroom community, and supports their retention of new material by highlighting connections between the content and students' biographies and background knowledge. Critical to this phase is the teacher's ability to revoice, a discourse move that involves listening to what students say and then re-uttering their understanding by reporting, repeating, rephrasing, or expanding upon what was shared (Forman, Larreamendy-Joerns, Stein, \& Brown, 1998; Herrera, Kavimandan, \& Holmes, 2011). The teacher revoices what was documented and collected from the activation (pre-assessment) phase earlier in the lesson to advance students' learning.

The Connection phase allows students to confirm and/or disconfirm predictions about the topic, concepts, and key vocabulary that were made in the Activation phase. They deepen their understanding of the content by utilizing text, peers, teacher, and other resources. During this phase, students interpret, question, analyze, discuss, evaluate, synthesize, and create. They are provided structured opportunities to apply and practice knowledge, skills, and processes in ways that integrate listening, speaking, reading, and writing.

The teacher also strategically configures groups to capitalize on the multifaceted benefits of collaborative peer interaction (Brock \& Raphael, 2005; Echevarria, Vogt, \& Short, 2008; Meltzer \& Hamann, 2004; Waxman \& Tellez, 2002). Although there is time for individual work and whole-group instruction, pairs and small groups often provide CLD learners with the most support. When designing groups, consideration is given to each of the four dimensions of the CLD student biography:

- Sociocultural: CLD learners often bring life experiences that provide a new lens for interpreting the curriculum and applying learning to real world issues.

- Linguistic: Connections between languages can improve all students' understanding of content-area vocabulary and language structures. More advanced English speakers can provide support for less advanced speakers of the same first language. Native English 
speakers can provide support for one another and for second language learners.

- Cognitive: Diverse learning styles can complement one another. Multiple perspectives on learning strategies and approaches to content-area processes can yield deeper understanding and greater retention for all students.

- Academic: Learners of similar levels of academic readiness can support one another. More academically advanced learners can serve as more capable peers for less advanced learners. Students who bring international schooling experiences often can provide alternative perspectives on curricular topics.

\section{Affirmation Phase}

In the Affirmation phase of the lesson, the teacher uses authentic assessment (Diaz-Rico \& Weed, 2006; Linn \& Miller, 2005) to document student progress, keeping in mind the varying linguistic and academic starting points of the learners in the classroom. Often student-created products provide the scaffolding CLD students need to best demonstrate their learning. The teacher affirms the progress made at both the individual and collective levels. In this context, every aspect of content-area learning and language acquisition is worthy of celebration in the classroom. The teacher, acting as an agent of affirmation, supports students in recognizing ways in which their background knowledge provided a foundation for their construction of new learning and understanding. Students gain opportunities to reflect on and discuss ways in which they maintained or revised their schemas to account for new learning.

Throughout the full progression of the lesson, students see their experiences, interests, and ideas as pivotal to their learning and that of their peers. With the goal of student ownership in mind, instruction utilizing this framework enables CLD students to see themselves as valued members and contributors to the learning community. Biography-driven instructional strategies, which are implemented across all three phases of the lesson, provide students with structured opportunities to become active learners within content-area classrooms.

\section{Biography-Driven Instruction Strategies}

Drawing on the existing research and literature in the field on effective practices in multicultural and multilingual classrooms, we developed strategies that serve as tools for implementing BDI with secondary learners of all cultural and linguistic backgrounds. These biography-driven instructional (BDI) strategies 
provide a blueprint as teachers scaffold instruction and explicitly capitalize on student assets to further content learning and academic language acquisition. By illustrating what culturally-responsive pedagogy looks, sounds, and feels like in classroom practice, BDI strategies support teachers' translation of knowledge and espoused beliefs into action.

A single BDI strategy is implemented across the Activation, Connection, and Affirmation phases of the lesson. Often a strategy is characterized by the use of a graphic organizer or manipulative jointly created by the teacher and student to document the learning process from the onset to the closing of the lesson. Multiple activities are embedded within each strategy, and these activities frequently integrate a focus on students' development of three types of learning strategies: cognitive strategies, metacognitive strategies, and social/affective strategies (Chamot \& O'Malley, 1994).

Cognitive strategies support students' manipulation of the content and include predicting, note-taking, using graphic organizers, making inferences, visualizing, and summarizing. Metacognitive strategies prompt learners to think about their thinking and learning processes. Such strategies include, for example, using selective attention and monitoring comprehension. Social/affective strategies help students use peers as a learning resource and create a low-anxiety learning environment.

BDI strategies guide teachers to use purposeful grouping and scaffolding techniques to ensure that all learners are actively engaged in learning. Although each strategy provides a unique structure for the overall learning process, all the strategies direct students to (a) activate their background knowledge, (b) make connections between what they already know and the new material, and (c) demonstrate their understanding and celebrate their learning. BDI strategies begin as teaching strategies, and educators are encouraged to adapt and tailor them creatively to meet the unique and evolving needs of their students and curricula. With repetition and use across multiple contexts, they soon become learning strategies that guide students in their construction of knowledge. BDI strategies promote self-confidence among students of all levels of English proficiency, allowing them to see that they can and will succeed in the classroom.

\section{BDI Strategy Close-up: Using Foldables in a High School Geometry Class}

The Foldable strategy (Herrera et al., 2011) supports teachers in providing an extended focus on academic vocabulary development throughout the lesson. Students become engaged as they create their individual Foldable using multiple pieces of paper (see Figure 1). They then have an opportunity to document their background knowledge about the key vocabulary of the lesson. After activating their funds of knowledge, prior knowledge, and academic knowledge, students are ready to share their initial associations with peers. Peer interaction and group discussion about each academic term/concept is interwoven throughout the 
remainder of the lesson to ensure that students have consistent opportunities to expand on connections between their background knowledge and the new

Figure 1. Completed foldable

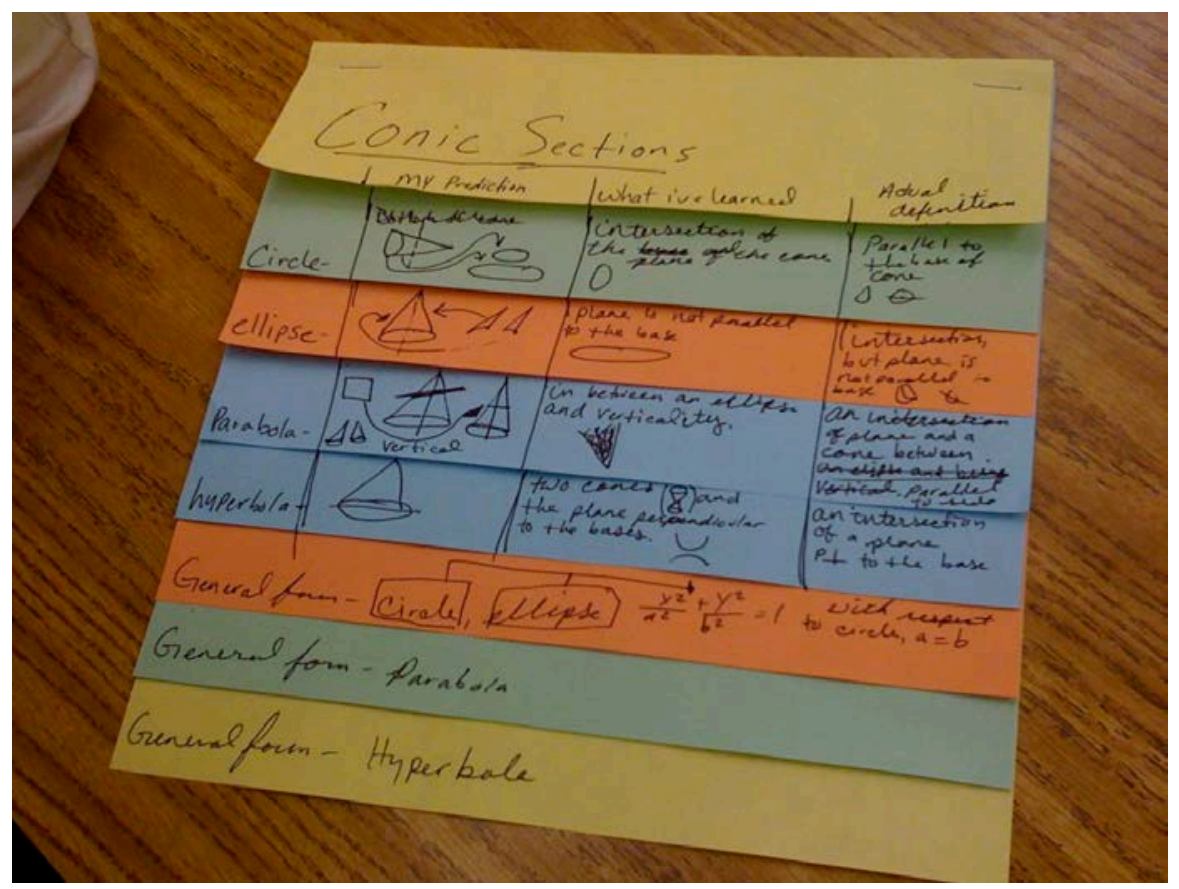

material, learn from and scaffold learning for peers, and practice using the academic vocabulary of the content area. Figure 2 provides a close-up look at how one high school teacher implemented the Foldable strategy with learners in a geometry class.

Figure 2. Foldable: One classroom's perspective

\section{One Classroom's Perspective}

\section{ACTIVATING}

Today was the first day that we covered conic sections with the group of 10th-graders. Since this was the first day for the concept, I realized that majority of my students were unfamiliar with the terms associated with conic sections. So, the first thing I did was put the words on the board for all my students to see. As I wrote the words, I had my students gather in groups, which I had planned in advance according to their language and academic proficiency. The first step of the strategy for my students was to predict what they thought each word meant, and for this step I allowed them to talk to each other. Some of my students had a

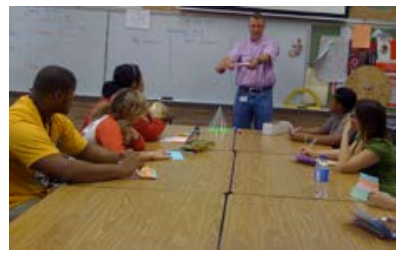




hard time with the words, so I showed them the realia to go with
the words and we talked about some of the things we could see in
the objects. With this additional support, they were able to predict
more about the words. As they finished the step, I had them
change their groups so they could share with other peers what
they came up with.
CONNECTING
The next step was looking for the words in our textbook. During
this part of the lesson, we also conducted a discussion regarding
the ways different words relate to conic sections. As they found a
word in context, students talked about the word with each other
and added the information in their Foldable, individually.
AFFIRMING
At the end of the lesson, we wrapped things up by dividing
students into their groups again. Each group was in charge of
becoming the expert on one vocabulary word and putting its
definition up on the board. The students worked together to
negotiate the sentence that best represented the word and to
create a picture that showed what the word meant.

\section{Current Research on Biography-Driven Instruction Strategies}

The BDI strategies have been the focus of research efforts by the Center for Multilingual Advocacy (CIMA) in the College of Education at Kansas State University since the fall of 2009. CIMA researchers sought to systematically collect observational data to explore the strategies' effects on the degree to which inservice teachers actually implemented culturally-responsive pedagogy. A limited number of observation tools are available, however, to explore instruction with second language learners systematically.

The Sheltered Instruction Observation Protocol (SIOP) (Echevarria, Vogt, \& Short, 2000) is one such tool, although it has been used most extensively as a teaching model. SIOP is aligned with existing literature on best practices and critical theoretical concepts related to teaching English language learners. However, it fails to support in-depth investigations of the situations and conditions that influence the instructional progression from pre-assessment of background knowledge to documentation of students' language and content learning.

The Center for Research on Education, Diversity and Excellence (CREDE) developed the Standards Performance Continuum (SPC) (Doherty, Hillberg, Epaloose, \& Tharp, 2002). This observational assessment tool is based on the Standards for Effective Pedagogy and Learning (Tharp, Estrada, Dalton, \& Yamauchi, 2000; CREDE, 2002), which can be briefly summarized as follows: 
1. Joint Productive Activity - Teacher and students producing together

2. Language Development - Developing language and literacy across the curriculum

3. Contextualization - Making meaning: Connecting school to students' lives

4. Challenging Activities - Teaching complex thinking

5. Instructional Conversation - Teaching through conversation

Although the theoretical foundation of the standards aligns with the literature on culturally-responsive practices for diverse learners, the SPC does not adequately allow in-depth exploration of many instructional practices known to support second language acquisition. The SPC, however, does emphasize many aspects of instruction that are pivotal to implementation of BDI, including: (a) development of academic language; (b) contextualization of academic content within students' knowledge and experiences from home, community, and school; (c) teachers' discourse moves; (d) student engagement and interaction; and (e) students' use of complex thinking. Given benefits such as these, CIMA researchers decided to use the SPC as the basis for the development of a new observation tool.

The Biography-Driven Performance (BDP) Rubric (Herrera, Perez, Kavimandan, Holmes, \& Miller, 2011; Murry, Herrera, Kavimandan, \& Perez, 2011) retains the emphasis on the Standards for Effective Pedagogy and Learning and continues to utilize a scale from 0-4, representing the five levels of enactment: Not Observed, Emerging, Developing, Enacting, and Integrating. However, it has been expanded to 22 indicators that provide elaboration on pedagogical aspects that are essential to effective instruction with CLD students. These fundamentals are emphasized within CIMA'S CLASSIC ${ }^{\odot}$ professional development program (Herrera, Murry, \& Pérez, 2008; Murry \& Herrera, 1999; Penner-Williams, Perez, Worthen, Herrera, \& Murry, 2010) and include, among others, the following:

- Pre-assessment of CLD students' background knowledge and experiences (Bauer \& Manyak, 2008; Herrera, 2010; Herrera et al., 2007; Tomlinson \& McTighe, 2006).

- Grouping configurations that reflect consideration for all four dimensions of the CLD student biography (sociocultural, linguistic, cognitive, and academic) and that promote English language acquisition (e.g., Herrera, 2010; Herrera, Kavimandan, \& Holmes, 2011; Herrera \& Murry, 2011).

- Recurrent use of CLD students' native language in their academic and English language development (Cummins, 1981; Goldenberg, 2008; Herrera \& Murry, 2011; Kibler, 2010).

- Low-risk learning and second language acquisition environments ( Herrera, 2010; Krashen, 1981, 1982; Meltzer \& Hamann, 2004). 
Subscale scores are generated by determining the average score from indicators in each of the five standards. A BDP composite score reflects the average of all 22 indicators.

\section{Overarching Results from Field Observations}

The BDP Rubric provided a means by which we could begin to investigate empirically the impact of both the $\mathrm{CLASSIC}^{\odot}$ professional development and the use of BDI strategies on teachers' instruction with CLD learners. Preliminary research into changes in teacher pedagogy associated with participation in the $\mathrm{CLASSIC}^{\odot}$ program and with use of BDI strategies began in Fall 2009. Between Fall 2009 and Spring 2011, CIMA researchers performed classroom observations of teachers in Kansas and Arkansas. The observations were intended to capture a complete lesson (30-110 minutes in duration) and were conducted in the teachers' typical classroom setting (i.e., grade level and content area).

A total of 175 secondary teachers were observed between 1 and 4 times. Approximately $59 \%$ of the observations occurred in middle school classrooms (grades 6-8), while 61\% took place in high school classrooms (grades 9-10). The average classroom population comprised 18 students, including 7 CLD learners, with 4 of these students receiving ESL services. Approximately $85 \%$ of classrooms included Hispanic students, $66 \%$ included African American students, $28 \%$ included Asian or Pacific Islander students, and 5\% included American Indian students. In addition to English, 22 languages were represented in classrooms; the most common languages spoken included Spanish (spoken in $84 \%$ of classrooms), Marshallese (6\%), Vietnamese (6\%), and Chinese (4\%).

Table 1. Descriptive Statistics

\begin{tabular}{lccc} 
& Mean & SD & $n$ \\
\hline $\begin{array}{l}\text { No Courses } \\
\text { Language Arts }\end{array}$ & 0.92 & 0.49 & 21 \\
$\quad$ Social Studies & 1.20 & 0.97 & 5 \\
$\quad$ STEM & 1.03 & 0.68 & 37 \\
Total & 1.01 & 0.64 & 63 \\
Taking Courses & & & 59 \\
$\quad$ Language Arts & 1.84 & 0.59 & 34 \\
$\quad$ Social Studies & 1.83 & 0.68 & 78 \\
$\quad$ STEM & 1.80 & 0.66 & 171 \\
Total & 1.82 & 0.64 & 27 \\
Courses + Strategy & & & 9 \\
$\quad$ Language Arts & 2.46 & 0.53 & 24 \\
$\quad$ Social Studies & 2.52 & 0.61 & 60 \\
$\quad$ STEM & 2.50 & 0.59 & 0.56 \\
Total & 2.48 & & \\
Note: Cohen's d effect size for taking courses and no courses comparison $\mathrm{d}=1.27(\mathrm{p}<$ \\
.001); taking courses and courses plus implementing a strategy comparison $\mathrm{d}=1.10(\mathrm{p}$ \\
$<.001)$.
\end{tabular}


Table 1 provides the descriptive statistics for observations conducted with teachers not enrolled (or prior to enrolling) in $\mathrm{CLASSIC}^{\odot}$ coursework, those conducted with teachers taking courses, and those conducted with teachers taking courses who also implemented a BDI strategy. Figure 3 illustrates the differences in secondary teachers' composite BDP scores. Large differences (i.e., statistically large effect sizes) were observed between teachers not taking courses, taking courses, and implementing a strategy. Figure 4 provides a breakdown by content area (i.e., Language Arts, Social Studies, STEM) of secondary teachers' composite BDP scores. Effects attributed to coursework and strategies did not differ across content areas.

Figure 3. Secondary Teachers' BDP Scores

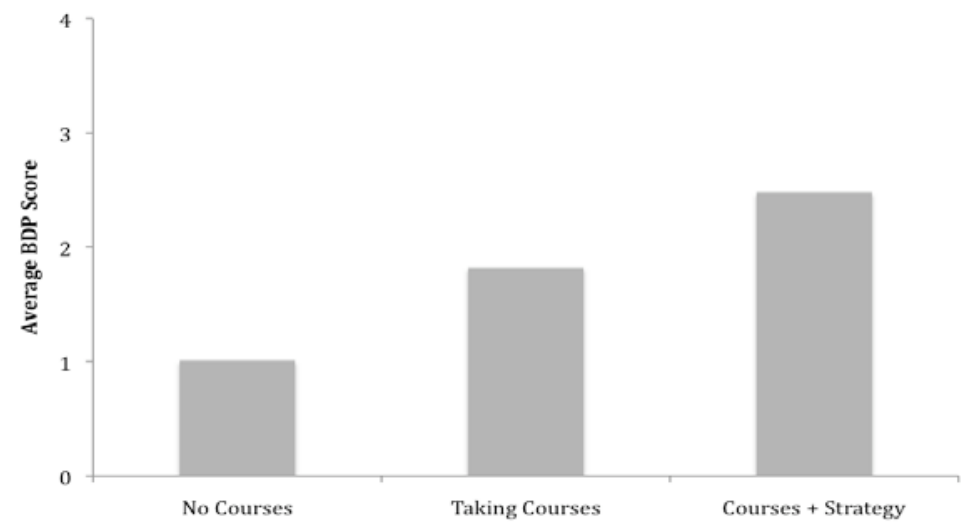

Figure 4. Secondary teachers' BDP scores by content area.

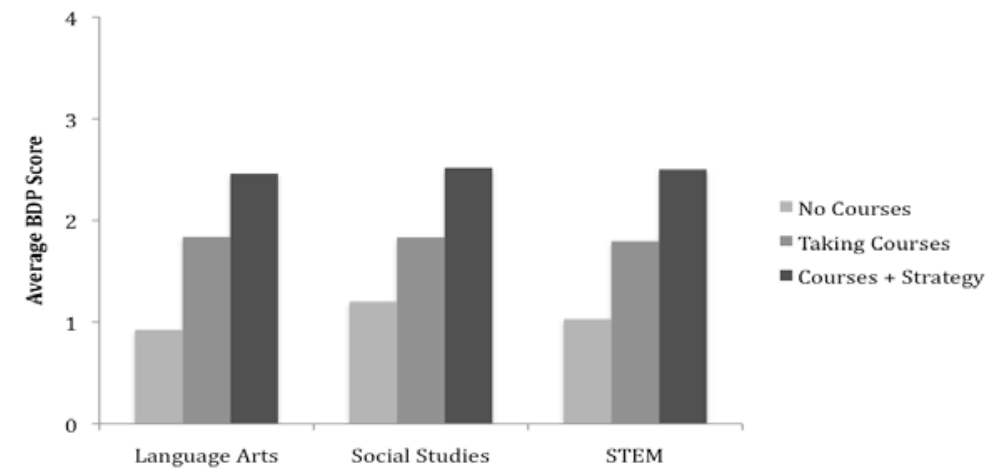

Herrera, Perez, Kavimandan, Holmes, and Miller (2011), for example, explored the effect of program involvement and strategy use with 239 Midwest public school teachers, including 106 secondary teachers. Results revealed that teachers who had completed the five-course program (completers) had significantly higher BDP scores during business-as-usual teaching conditions than those who were in the first course of the program (beginners), and those in their first course outperformed those who were not involved in the program and had no ESL endorsement. Observations of program beginners and completers during implementation of a BDI strategy yielded significantly higher BDP scores for both groups, such that the effect size of the difference in teacher performance 
under the two conditions was 2.6 times larger than that of the difference between program beginners and completers in the business-as-usual condition. The results of this study indicate that BDI strategies are promising tools for supporting secondary teachers' ability to translate theoretical knowledge of best practice with CLD students into actual classroom practices.

In another recent study, Perez, Holmes, Miller, and Fanning (2012) investigated differences in pedagogy among 58 Midwest teachers by grade level taught (elementary vs. secondary) and strategy use (strategy vs. no strategy). Study results indicated that the BDP scores of the 39 elementary teachers were significantly higher than those of the 19 secondary teachers when neither group was implementing a strategy. However, in the strategy condition, there was no significant difference between the BDP scores of the secondary teachers and those of the elementary teachers, and both groups of teachers performed significantly higher on the BDP measure.

In a mixed-method study, MacDonald, Miller, Worthen, Baptiste, and Herrera (2012) explored the use of BDI strategies in K-12 science and math instruction. The researchers found that although science teachers outperformed math teachers on the BDI measure in both the no-strategy and strategy condition, BDI strategy use among all 39 teachers yielded significant increases in BDI scores for the teachers of both content areas. Moreover, the teachers' BDP scores increased at similar rates regardless of content area. Through interview data, this study also revealed that teachers found BDI strategies to be effective tools for improving the learning outcomes of CLD students.

Taken together, the results of observational research on the use of BDI strategies to improve instruction for students in diverse classroom settings are promising. Secondary teachers who implement BDI strategies are more likely to perform higher on the BDP measure. Higher BDP scores are indicative of greater fidelity to the theoretical model of biography-driven instruction-a model designed to support teachers in providing culturally-responsive teaching practices as a means to improving the academic achievement of CLD learners. The strength of using systematic classroom observations to explore teaching practices lies in the researcher's ability to move beyond self-report measures to more objectively capture observable differences in teacher behaviors. Ongoing and future research will explore the characteristics of individual BDI strategies that lead to greater instructional effectiveness in multicultural classrooms.

\section{Conclusion}

At a time when linguistic, racial, and ethnic student diversity in secondary classrooms has become the norm rather than the exception, preservice teachers, inservice teachers, and teacher educators need to become skilled at capitalizing on the assets that CLD students bring to the classroom. This process must involve attention to culture and language that goes beyond theory and rhetoric. 
Supporting the development of culturally-responsive educators who are prepared to meet the needs of second language learners requires that educators have access to instructional models, frameworks, and tools that are flexible enough to be used effectively in all secondary classrooms, regardless of content area, adopted curricula, and classroom composition.

Biography-driven instruction lends itself to wide application because of the student-centered nature of the model. Using individual learners' sociocultural, linguistic, cognitive, and academic biographies as the basis for planning and subsequent instruction and assessment ensures that each learner will see himself/herself reflected in the learning process. Emphasis on students' funds of knowledge, prior knowledge, and academic knowledge within each lesson phase enables the type of individualized instruction that allows teachers to be truly responsive to CLD students' assets and needs. As Earl (2003) so eloquently explains, "Once you have a sense of what each student holds as 'given' or 'known' and what he or she needs in order to learn, differentiation is no longer an option. It is an obvious response" (pp. 86-87).

BDI strategies, which are employed as the application component of the proposed framework for linguistic and academic development, provide teachers with additional support as they make the leap from theory to practice when implementing biography-driven instruction. Research to date indicates that use of BDI strategies across a range of content areas and by secondary teachers with varying amounts of professional development on biography-driven instruction consistently yields improved performance on the BDP measure of effective teaching. For teachers who desire to provide instruction that addresses the multifaceted needs of secondary CLD students, BDI strategies can serve as an evidence-based route to more culturally responsive pedagogy.

\section{Notes}

1. Descriptors used here reflect those used by the U.S. Department of Education data source.

\section{References}

Aud, S., Hussar, W., Kena, G., Bianco, K., Frohlich, L., Kemp, J., \& Tahan, K. (2011). The condition of education 2011 (NCES 2011-033). U.S. Department of Education, National Center for Education Statistics. Washington, DC: U.S. Government Printing Office.

Banks, J. A. (1989). Approaches to multicultural curriculum reform. Trotter Review, 3(3), Article 5. Available at http://scholarworks.umb.edu/ trotter_review/vol3/iss $3 / 5$ 
Banks, J. A. (1998). Educating citizens in a multicultural society. New York. NY: Teachers College Press.

Batalova, J., \& McHugh, M. (2010). Top languages spoken by English language learners nationally and by state. Washington, DC: Migration Policy Institute.

Bauer, E. B., \& Manyak, P. C. (2008). Creating language-rich instruction for English-language learners. The Reading Teacher, 62(2), 176-178.

Bomer, R., Dworin, J. E., May, L., \& Semingson, P. (2008). Miseducating teachers about the poor: A critical analysis of Ruby Payne's claims about poverty. Teachers College Record, 110(12), 2497-2531.

Brock, C. H., \& Raphael, T. E. (2005). Windows to language, literacy, and culture. Newark, DE: International Reading Association.

Center for Research on Education, Diversity \& Excellence (CREDE). (2002). The Standards for Effective Pedagogy and Learning. Retrieved from http://gse.berkeley.edu/research/credearchive/standards/stand_indic.shtml

Chamot, A. U., \& O'Malley, J. M. (1994). The CALLA handbook: Implementing the cognitive academic language learning approach. Reading, MA: Addison-Wesley.

Cummins, J. (1981). The role of primary language development in promoting educational success for language minority students. In C. F. Leyba (Ed.), Schooling and language minority students: A theoretical framework (pp. 349). Los Angeles: Evaluation, Dissemination and Assessment Center, CSULA.

Diaz-Rico, L. T., \& Weed, K. Z. (2006). The cross-cultural, language, and academic development handbook: $A$ complete $K-12$ reference guide $\left(3^{\text {rd }}\right.$ ed.). Boston, MA: Allyn and Bacon.

Doherty, R. W., Hilberg, R. S., Epaloose, G., \& Tharp, R. G. (2002). Standards performance continuum: Development and validation of a measure of effective pedagogy. Journal of Education Research, 96, 78-89.

Earl, L. M. (2003). Assessment as learning: Using classroom assessment to maximize student learning. Thousand Oaks, CA: Corwin Press.

Echevarria, J., Vogt, M., E., \& Short, D. (2000). Making content comprehensible for English Language Learners: The SIOP model. Boston, MA: Allyn \& Bacon.

Echevarria, J., Vogt, M. E., \& Short, D. (2008). Making content comprehensible for English language learners: The SIOP model ( $3^{\text {rd }}$ ed.). Boston, MA: Allyn \& Bacon.

Feistritzer, C. E. (2011). Profile of teachers in the U.S. 2011. Washington, DC: National Center for Education Information. 
Forman, E. A., Larreamendy-Joerns, J., Stein, M. K., \& Brown, C. A. (1998). "You're going to want to find out which and prove it": Collective argumentation in a mathematics classroom. Learning and Instruction, 8(6), 527-548.

Gay, G. (2000). Culturally responsive teaching: Theory, research, \& practice. New York NY: Teachers College Press.

Gay, G. (2002). Preparing for culturally responsive teaching. Journal of Teacher Education, 53(2), 106-116.

Goldenberg, C. (2008). Teaching English language learners: What the research does-and does not-say. American Educator, 32(2) 8-44.

Herrera, S. (2010). Biography-driven culturally responsive teaching. New York, NY: Teachers College Press.

Herrera, S. G., Kavimandan, S. K., \& Holmes, M. A. (2011). Crossing the vocabulary bridge: Differentiated strategies for diverse secondary classrooms. New York, NY: Teachers College Press.

Herrera, S., \& Murry, K. (2011). Mastering ESL and bilingual methods: Differentiated instruction for culturally and linguistically diverse (CLD) students $\left(2^{\text {nd }}\right.$ ed.). Boston: Allyn and Bacon.

Herrera, S., Murry, K., \& Cabral, R. M. (2007). Assessment accommodations for classroom teachers of culturally and linguistically diverse students. Boston, MA: Allyn \& Bacon.

Herrera, S. G., Murry, K. G., \& Pérez, D. R. (2008). CLASSIC: Transforming hearts and minds. In M. E. Brisk (Ed.), Language, culture, and community in teacher education (pp. 149-173). Mahwah, NJ: Lawrence Erlbaum.

Herrera, S. G., Perez, D. R., Kavimandan, S., Holmes, M. A., \& Miller, S. S. (2011, April). Beyond reductionism and quick fixes: Quantitatively measuring effective pedagogy in the instruction of culturally and linguistically diverse (CLD) students. Paper presented at the annual conference of the American Educational Research Association, New Orleans, LA.

Kibler, A. (2010). Writing through two languages: First language expertise in a language minority classroom. Journal of Second Language Writing, 19(3), 121-142.

Krashen, S. D. (1981). Second language acquisition and second language learning. London, UK: Pergamon Press.

Krashen, S. (1982). Principles and practice in second language acquisition. Oxford, UK: Pergamon Press.

Krashen, S. D. (1984/2002). Bilingual education and second language acquisition theory. In C. F. Leyba, Schooling and language minority students: A theoretical framework (2nd ed., pp. 47-75). Los Angeles, CA: Legal Books. 
Ladson-Billings, G. (1995). But that's just good teaching! The case for culturally relevant pedagogy. Theory into Practice, 34(3), 159-165.

Linn, R. L., \& Miller, M. D. (2005). Measurement and assessment in teaching $\left(9^{\text {th }}\right.$ ed.). Upper Saddle River, NJ: Prentice Hall.

MacDonald, G. L., Miller, S., Worthen, D. G., Baptiste, P., \& Herrera, S. (2012). A biography-driven approach to "good teaching practices" for culturally and linguistically diverse students in science education. Manuscript submitted for publication.

Marzano, R. J., Gaddy, B. B., \& Dean, C. (2000). What works in classroom instruction. Aurora, CO: Mid-continent Research for Education and Learning (McREL).

Meltzer, J., \& Hamann, E. T. (2004). Meeting the literacy development needs of adolescent English language learners through content-area learning. Part one: Focus on motivation and engagement. Providence, RI: The Education Alliance, Brown University.

Moll, L. C., Amanti, C., Neff, D., \& Gonzalez, N. (1992). Funds of knowledge for teaching: Using a qualitative approach to connect homes and classrooms. Theory into Practice, 31(2), 132-141.

Morrison, K. A., Robbins, H. H., \& Rose, D. G. (2008). Operationalizing culturally relevant pedagogy: A synthesis of classroom-based research. Equity \& Excellence in Education, 41(4), 433-452.

Murry, K., \& Herrera, S. (1999). CLASSIC impacts: A qualitative study of ESL/BLED programming. Educational Considerations, 26(2), 11-19.

Murry, K., Herrera, S., Kavimandan, S., \& Perez, D. (2011). Translating standards into practice with ELA students. The Advocate 19(1), 49-55.

National Center on Response to Intervention. (2010, March). Essential components of RTI - A closer look at response to intervention. Washington, DC: U.S. Department of Education, Office of Special Education Programs, Author.

Nieto, S. (2000). Affirming diversity: The sociopolitical context of multicultural education $\left(3^{\text {rd }}\right.$ ed.). New York: Addison Wesley Longman.

Nieto, S. (2002). Language, culture, and teaching: Critical perspectives for a new century. Mahwah, NJ: Lawrence Erlbaum.

Penner-Williams, J., Perez, D., Worthen, D. G., Herrera, S., \& Murry, K. (2010). A CLASSIC approach to collaboration: Documenting a multi-state university and multi-school district partnership. In J. J. Slater \& R. Ravid (Eds.), Collaboration in Education (pp. 161-167). New York, NY: Routledge.

Perez, D., Holmes, M., Miller, S., \& Fanning, C. (2012). Biography-driven strategies as the great equalizer: Universal conditions that promote $\mathrm{K}-12$ culturally responsive teaching. Journal of Curriculum and Instruction, 6(1), 25-42. 
Santamaria, L. J. (2009). Culturally responsive differentiated instruction: Narrowing gaps between best pedagogical practices benefitting all learners. Teachers College Record, 111(1), 214-247.

Smith, J. P., III, diSessa, A. A., \& Roschelle, J. (1993/1994). Misconceptions reconceived: A constructivist analysis of knowledge in transition. Journal of the Learning Sciences, 3(2), 115-163.

Sousa, D. A. (2006). How the brain learns ( $3^{\text {rd }}$ ed.). Thousand Oaks, CA: Corwin Press.

Tharp, R. G., Estrada, P., Dalton, S. S., \& Yamauchi, L. (2000). Teaching transformed: Achieving excellence, fairness, inclusion, and harmony. Boulder, CO: Westview Press.

Thomas, W. P., \& Collier, V. P. (1997). School effectiveness for language minority students (NCBE Resource Collection Series No. 9). Washington, DC: National Clearinghouse for Bilingual Education.

Tomlinson, C. A. (2001). How to differentiate instruction in mixed-ability classrooms $\left(2^{\text {nd }}\right.$ ed.). Alexandria, VA: Association for Supervision and Curriculum Development.

Tomlinson, C. A., \& McTighe, J. (2006). Integrating differentiated instruction and understanding by design: Connecting content and kids. Alexandria, VA: Association for Supervision and Curriculum Development.

Vygotsky, L. S. (1978). Mind in society: The development of higher psychological processes (M. Cole, V. John-Steiner, S. Scribner, \& E. Souberman, Eds.). Cambridge, MA: Harvard University Press.

Waxman, H. C., \& Tellez, K. (2002). Research synthesis on effective teaching practices for English language learners. Philadelphia, PA: Mid-Atlantic Laboratory for Success. 